\title{
Wolves do not join the dance: Sophisticated aggression control by adjusting to human social signals in dogs
}

\author{
Márta Gácsi ${ }^{\mathrm{a}, *}$, Judit Vas ${ }^{\mathrm{b}}$, József Topál ${ }^{\mathrm{c}}$, Ádám Miklósi ${ }^{\mathrm{a}, \mathrm{b}}$ \\ a MTA-ELTE Comparative Ethology Research Group, Budapest, Hungary \\ b Eötvös Loránd University, Department of Ethology, Budapest, Hungary \\ ${ }^{\mathrm{c}}$ Research Centre for Natural Sciences, Institute of Cognitive Neuroscience and Psychology, Hungarian Academy of Sciences, \\ Budapest, Hungary
}

\section{A R T I C L E I N F O}

\section{Article history:}

Accepted 17 February 2013

Available online $\mathrm{xxx}$

\section{Keywords:}

Interspecific play

Dog-human interaction

Competitive game

Dog-wolf comparison

\begin{abstract}
A B S T R A C T
In this study we aimed to investigate novel aspects of dogs' comprehension of human social behaviours by revealing potential differences in the responses of wolves and dogs when they interact with a human in socially ambiguous situations.

In Experiment 1, pet dogs $(N=13)$ and hand-reared wolves $(N=13)$ encountered a stranger who approached them first in a friendly, then a threatening way, and finally switched back to friendliness again (Approaching stranger; AS) while the passive owner/caregiver was standing close to the subjects. In contrast to dogs, wolves avoided eye contact with both the caregiver and the stranger, however, only dogs showed aggressive displays towards the stranger.

In Experiment 2, the same subjects were tested in an Object guarding (OG) situation. A familiar woman, communicating the playful nature of the encounter, pretended to aim at taking away her belt-bag from the subjects trying to make them respond with guarding behaviour. Finally, she tried to take away the object without using dominant/threatening behaviour. During the Game episode some dogs and wolves showed guarding displays, but only dogs switched their responses twice and finally allowed the human take hold of the object. All dogs but none of the wolves gazed at the owner/caregiver during the test.

In Experiment 3, we tested trained Belgian shepherd dogs $(N=13)$ in AS, OG, and in a Food guarding (FG) situation. In FG a familiar woman challenged the subject to guard a bone by applying enticement but otherwise not communicating the playful/pretended nature of the encounter. Dogs displayed aggressive behaviours in all three situations as a response to the human's behaviour. In AS they adjusted their behaviour from passive/friendly to aggressive and then friendly again, according to the switch in the human partner's actions. In OG and FG situations, after showing aggressive guarding displays they allowed the human to take away the guarded object, both the bag and the food. A characteristic high-pitched vocalisation observed during both guarding situations, typically before the first aggressive display, could refer to the dogs' ambivalent emotions. This suggests that the human's challenging behaviour alone might be effective to evoke a simulated guarding behaviour. Our results support the view that dogs have advanced abilities and readiness to combine seemingly contradicting behaviour responses to respond to human behaviours or expectations, whilst even hand-reared and extensively socialised wolves tend to display less human centred behaviours and adjust their behaviours less to that of humans' in interspecific situations.
\end{abstract}

(c) 2013 Published by Elsevier B.V.

\footnotetext{
* Corresponding author at: MTA-ELTE Comparative Ethology Research Group, Pázmány P. stny 1/c. Budapest, 1117, Hungary. Tel.: +36 1381 2179; fax: +3613812180.

E-mail address: marta.gacsi@gmail.com (M. Gácsi).
} 


\section{Introduction}

It has been recently argued that the dog is unique among domesticated species due to its special evolutionary history and developmental socialisation in the human environment, thus it may provide a promising model in studying some aspects of complex human social behaviour (Topál et al., 2009). Dogs' highly developed social understanding can help them predict the behaviour of humans during coordinated interactions. Whilst some argue that dogs are able to comprehend some of the motivational, emotional or intentional aspects of complex human social behaviours (e.g. Bekoff, 1998), others maintain that dogs' skills can be explained by their ability to rapidly learn to show relevant, that is, previously reinforced behaviours (Reid, 2009).

Recently, the investigation of dog-human competitive interactions has received growing attention in both agonistic (see e.g. van der Borg et al., 1991; O'Sullivan et al., 2008) and playful (see e.g. Rooney and Bradshaw, 2003; Mitchell 1991; Tóth et al., 2009) situations, but the comparative and combined analysis of the two is lacking. Despite the fact that dog owners and trainers claim that they routinely utilise complex social cues, for example, in the course of defence sport training in order to evoke aggressive displays during a controlled, highly stereotyped 'game' situation, we have very little experimental data on how these stimuli are functioning in dog-human interactions.

Some have suggested that social play is one of the most complex forms of social interaction that may include also some cognitive elements such as deception (Mitchell and Thompson, 1993), and intentionality or pretence (Mitchell, 2002; Bekoff, 1998). Nevertheless, it can be challenging to define interspecific play at the behaviour level. Carnivores tend to perform predominantly agonistic and predatory behaviours during social play. The actions are often exaggerated when compared to the same actions performed in a non-play situation (Bekoff, 1981). The play actions are performed in role reversals in which the existing dominant-subordinate relationships are claimed not to play a major role, that is, in order to maintain play both partners should be willing to take any roles in play (Pellis and Pellis, 1998). Recent results, however, contradict the notion that more advantaged individuals consistently relinquish their advantage to facilitate play (Bauer and Smuts, 2007), and role reversals were only observed during some type of behaviours (e.g. chases and tackles). Importantly, play signals help to ensure that any harmful action is not taken seriously both between conspecifics and in dog-human play (Fagen, 1981; Bekoff, 1998). Moreover, self-handicapping and play signalling work together to communicate playful intent and reinforce existing roles (Bauer and Smuts, 2007).

The comparative analysis of dog and wolf behaviour during competitive game situations with humans could provide further insight into the claimed flexibility in dogs' interspecific social behaviours. Whilst socialisation to humans is a natural process in dogs, this is not true for the wolf. Thus, any comparative work should utilise animals that have been socialised to comparable levels, especially during early development. Such studies have already revealed some crucial differences in the human related social behaviours of the two species. For example, compared to wolf pups, dog puppies' more intense social interest towards humans is accompanied by relatively greater sensitivity to human behavioural cues (Miklósi et al., 2003; Virányi et al., 2008) and less aggression during non-competitive inter-specific interactions (Gácsi et al., 2005; 2009). Moreover, in contrast to dogs, wolves do not show human analogue attachment behaviour to their owners (Topál et al., 2005).

The aim of the present study was twofold. First, we wanted to reveal potential differences in the social behaviour of extensively socialised, hand-reared wolves and pet dogs when interacting with a human in socially ambiguous situations. Second, we introduced a competitive, game-like situation to investigate novel aspects of dogs' comprehension of human social behaviour.

\section{Experiment 1}

In the first experiment, we compared the responses of wolves and dogs to an unfamiliar human who showed signs of friendliness and mild threat during alternate approaches. Dogs' agonistic behaviour and their flexibility to adjust to an unfamiliar human's behaviour in non-playful situations was already studied in a test situation that had been designed to evoke moderate stress in the subjects because an unfamiliar person's friendly behaviour cues were suddenly switched to threatening signals (Vas et al., 2005). So far, this test has already been applied in several studies investigating the social competence and human directed aggression of dogs (Vas et al., 2005; 2008; Klausz et al., 2009, Győri et al., 2010).

Accepting the notion that domestication has led to extreme flexibility of the dogs' situation-relevant behaviour in their interactions with an unfamiliar human (Vas et al., 2005), we can assume that apparent switches of the human behavioural signals evoke situation-relevant behaviour responses only from the dogs (or at least dogs are more sensitive than wolves in this respect). If, however, individual socialisation indeed is a crucial factor in the emergence of subjects' ability to synchronise their behaviour in response to the subtle changes in the mode of approaching then we can expect comparable behavioural adjustments in dogs and wolves.

\subsection{Method}

\subsubsection{Subjects}

Pet dogs $(N=13$, six males and seven females, mean age \pm SD: $2.0 \pm 1.4$ years; 3 border collies, 2 mongrels, 2 Belgian shepherds, 1 mudi, vizsla, beagle, poodle, schnauzer, and cocker spaniel) and hand-reared grey wolves $(N=13$, eight males and five females, mean age \pm SD: $2.2 \pm 1.6$ years) participated in this experiment. Seven of the dogs came from a multi dog household.

All dogs were characterised by their owners as well socialised, friendly individuals. All of them previously attended puppy courses $(N=8)$ and/or basic obedience training courses $(N=10)$. Most of them $(N=9)$ lived in the garden and they were not walked daily. 
All wolves were hand-reared in their caregivers' homes separated from the mother and the littermates at the age of 2-5 days (see Kubinyi et al., 2007 for more details). They were extensively socialised to humans during the first 4 months of their life living in the home of the caregiver, spending 24 hours a day with the caregiver and being walked regularly on leash. They attended a dog school where they could meet and interact with unfamiliar dogs and humans (most wolves attended a puppy course), and participated in behavioural tests that included object game situations. At the time of the present experiment, they lived in a wolf park in packs where they had daily contact with several familiar humans (who regularly entered their enclosure and interacted with them). They also had regular contact with unfamiliar humans outside the enclosure individually, when they met visitors, participated in film shootings, shows, and behaviour tests (which included joined manipulation of objects with humans). The wolves were tested with the caregivers who had hand-reared them and had regular contact with them. None of the animals was castrated.

\subsubsection{Procedure}

The AS took place at a location that was familiar to the subjects: in the garden beside the wolves' enclosure and in a park in the case of the dogs. Subjects encountered an unfamiliar woman experimenter(E1) who showed definite signs of friendliness and threat during alternate approaches. The encounters were video recorded from the side by a woman (E2) for later evaluation. The experimental procedure used was identical to the study of Vas et al. (2005), thus we provide here only a short description.

The subject was tethered with a $2 \mathrm{~m}$ long leash to a tree thus allowing it to move freely to some extent and respond with avoidance during the test. The owner stood half a metre behind the subject without moving or speaking. The test trial consisted of two or three subsequent episodes depending on the subject's reactions.

1. Friendly approach: E1 stood $5 \mathrm{~m}$ away, facing the subject and called it by its name. If the subject gazed at her face then she started to approach it in normal walking speed, speaking kindly to the animal and tried to maintain continuous eye contact with it. If she reached the animal, she petted it gently. Only subjects that did not show aggression or active avoidance during the Friendly approach episode participated in the second episode of the test. (One wolf out of the 13 had to be excluded because it actively avoided the friendly approaching E1.) After having stroked the animal, E1 went back to her starting position, and as soon as the owner got the animal to its initial position, the second episode was started.

2. Threatening approach: This time E1 moved slowly and haltingly and looked steadily in the eye of the subject without any verbal communication. If the animal interrupted the eye contact (moved away or turned its head away), she tried to attract its attention by some neutral noise (coughing, scratching the ground) and/or approaching from a different direction. The trial was terminated if the subject performed one of the five behaviour patterns described below.
As reported by Vas et al. (2005), based on their final behaviour, subjects were classified into five different response categories:

Friendly - the subject might bark or growl or step back at the beginning of the approach, but this should be a very short response. If the subject finally kept looking at E1 and did not moved off or show aggressive displays, then E1 fully approached and finally petted it. If the subject wagged its tail or licked E1's hand or face it was categorised as Friendly.

Passive - the same behaviours as in the case of the Friendly category but at the end the subject did not wag its tail or lick E1.

Passive avoidant - the subject might bark or growl or step back at the beginning of the approach, but this should be a very short response. The subject finally interrupted the eye contact with E1 and averted its gaze without barking or growling.

Active avoidant - the subject might bark or growl but not permanently. The subject finally moved away while keeping eye contact with $\mathrm{E} 1$.

Threatening - the subject barked or growled permanently and/or tried to attack E1.

3. Calling: If the subject belonged into any of the latter three categories, after terminating the Threatening approach E1 stepped back, sat on her heels and called the subject kindly to her for 10 seconds. If the subject approached her, she stroked it.

\subsubsection{Behaviour variables and data analyses}

For most behaviour variables (see Table 1), occurrence or non-occurrence during the test was noted because exact duration could not be determined and the length of the tests varied depending on the reaction of the subjects. In addition to the variables listed in Table 1, the subjects' behaviour was categorised into response categories both in the Friendly approach and the Threatening approach episodes (see above). Response categories were derived from the listed variables.

The records were coded by observers knowledgeable about wolf and dog behaviour (J. V. and M. G.). Inter-observer agreements for the variables and response categories were assessed by means of parallel coding of the $20 \%$ of the animals by two trained observers. High values were calculated in all cases (Kappa coefficients: tail wag: 0.87; gaze at owner: 0.77; approach owner: 1.0; gaze avert: 0.82; growl: 0.77; bark: 0.82; attack: 0.84). Chi-square test of homogeneity or Fisher's exact test were applied when the distribution of the subjects in the different behaviour categories was analysed. (Note that in case of Fisher's exact test only $\mathrm{p}$ values are given.) Latency to gaze avert after establishing eye contact was analysed by Mann-Whitney test.

\subsection{Results}

During the Friendly approach all dogs and all but two wolves showed passive or friendly behaviours (Dog: friendly $N=5$, passive $N=8$; Wolf: friendly $N=6$, passive $N=5$, passive avoiding $N=1$, active avoiding $N=1$ ). Dogs displayed friendly behaviour by tail wagging, and friendly wolves mainly licked the hand or face of E1. The 


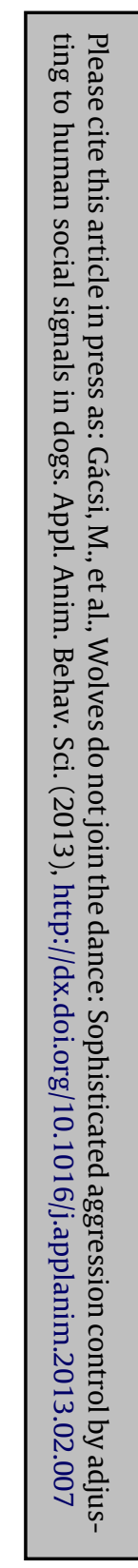

The names and definitions of behavioural variables, and the list of tests where they were coded.

Variables During threatening stranger episode in AS and game episode in OG and FG

\begin{tabular}{|c|c|c|c|c|c|c|c|c|c|c|}
\hline vallabies & Tail wag & Approach owner & Gaze at owner & $\begin{array}{l}\text { Latency of } \\
\text { avert gaze }\end{array}$ & $\begin{array}{l}\text { High-pitched } \\
\text { vocalise }\end{array}$ & Growl & Bark & Attack & Snap & Play signals \\
\hline Definitions & $\begin{array}{l}\text { Move tail } \\
\text { sidelong }\end{array}$ & $\begin{array}{l}\text { Get closer than } \\
0,5 \mathrm{~m}\end{array}$ & $\begin{array}{l}\text { Turn head } \\
\text { towards } \\
\text { owner's upper } \\
\text { body }\end{array}$ & $\begin{array}{l}\text { Time elapsed } \\
\text { till first } \\
\text { averting gaze }\end{array}$ & $\begin{array}{l}\text { Whine or } \\
\text { "screaming" } \\
\text { bark or growl }\end{array}$ & $\begin{array}{l}\text { Growl, grunt or } \\
\text { snarl }\end{array}$ & Bark, yelp & $\begin{array}{l}\text { Move towards } \\
\text { e2 stretching } \\
\text { leash + growl or } \\
\text { bark or snap }\end{array}$ & $\begin{array}{l}\text { A bite attempt } \\
\text { towards the e } \\
\text { hand }\end{array}$ & $\begin{array}{l}\text { Display play } \\
\text { bow or pawing }\end{array}$ \\
\hline Type/unit & Yes-no & Yes-no & Yes-no & Second & Yes-no & Yes-no & Yes-no & Yes-no & Yes-no & Yes-no \\
\hline AS - Exp. 1 & $\mathrm{x}$ & $\mathrm{x}$ & $\mathrm{x}$ & $\mathrm{x}$ & & $\mathrm{x}$ & $\mathrm{x}$ & $\mathrm{x}$ & & \\
\hline OG - Exp. 2 & $\mathrm{x}$ & $\mathrm{x}$ & $\mathrm{x}$ & $\mathrm{x}$ & & $\mathrm{x}$ & $\mathrm{x}$ & $\mathrm{x}$ & $\mathrm{x}$ & $\mathrm{x}$ \\
\hline AS - Exp. 3 & $\mathrm{x}$ & $\mathrm{x}$ & $\mathrm{x}$ & & $\mathrm{x}$ & $\mathrm{x}$ & $\mathrm{x}$ & $\mathrm{x}$ & & \\
\hline OG - Exp. 3 & $\mathrm{x}$ & $\mathrm{x}$ & $\mathrm{x}$ & & $\mathrm{x}$ & $\mathrm{x}$ & $\mathrm{x}$ & $\mathrm{x}$ & $\mathrm{x}$ & $\mathrm{x}$ \\
\hline FG- Exp. 3 & $\mathrm{x}$ & $\mathrm{x}$ & $\mathrm{x}$ & & $\mathrm{x}$ & $\mathrm{x}$ & $\mathrm{x}$ & $\mathrm{x}$ & $\mathrm{x}$ & $\mathrm{x}$ \\
\hline \multirow[t]{2}{*}{ Variables } & & \multicolumn{9}{|c|}{ during calling episode in AS and take away episode in OG, FG } \\
\hline & & \multicolumn{2}{|l|}{ Tail wag, lick } & \multicolumn{2}{|c|}{ Aggressive displays } & \multicolumn{2}{|l|}{ Approach e1 } & \multicolumn{2}{|l|}{ Grab object } & Allow take away \\
\hline \multicolumn{2}{|l|}{ Definitions } & \multicolumn{2}{|c|}{$\begin{array}{l}\text { Move tail sidelong, } \\
\text { lick face/hand }\end{array}$} & \multicolumn{2}{|l|}{ Growl, snap, bite } & \multicolumn{2}{|l|}{$\begin{array}{l}\text { Close enough to } \\
\text { physical contact }\end{array}$} & \multicolumn{2}{|l|}{ Held it in mouth } & $\begin{array}{l}\text { Object/food can be } \\
\text { taken in } 3 \mathrm{~s}\end{array}$ \\
\hline \multicolumn{2}{|l|}{ Type/unit } & \multirow{2}{*}{\multicolumn{2}{|c|}{ Yes-no }} & \multicolumn{2}{|l|}{ Yes-no } & \multicolumn{2}{|l|}{ Yes-no } & \multirow{2}{*}{\multicolumn{2}{|c|}{ Yes-no }} & \multirow[t]{3}{*}{ Yes-no } \\
\hline AS - Exp. 1 & & & & $\mathrm{x}$ & & $\mathrm{x}$ & & & & \\
\hline \multicolumn{2}{|l|}{ AS - Exp. 3} & \multicolumn{2}{|l|}{$\mathrm{x}$} & \multicolumn{2}{|l|}{$\mathrm{x}$} & \multicolumn{2}{|l|}{$\mathrm{x}$} & & & \\
\hline OG - Exp. 2,3 & & \multirow{2}{*}{\multicolumn{2}{|c|}{$\begin{array}{l}x \\
x\end{array}$}} & $\mathrm{x}$ & & & & $\mathrm{x}$ & & $\mathrm{x}$ \\
\hline \multicolumn{2}{|l|}{ FG- Exp. 3} & & & \multicolumn{4}{|l|}{$\mathrm{x}$} & & & $\mathrm{x}$ \\
\hline
\end{tabular}




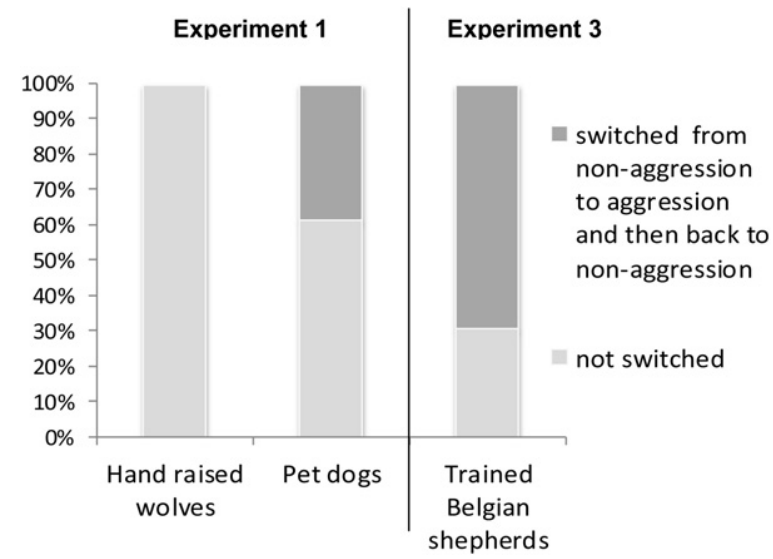

Fig. 1. Behaviour adjustment in the Approaching stranger test in Experiments 1 and 3 . The proportion of the subjects that switched from non-aggressive behaviour (Friendly approach: friendly, passive or avoidant) to some type of threatening behaviour (Threatening approach: bark, growl, attack) and then back to non-aggressive behaviour (Calling episode).

distribution of the individual dogs and wolves across the response categories did not differ $\left(\chi^{2}{ }_{(2)}=2.783, p=0.249\right)$.

During the Threatening approach we found marked differences between the two species. Only two wolves gazed at their owners during the test, while dogs had a pronounced tendency (10 out of the 13) to look at the owner $(p=0.005)$. Wolves averted their gaze from the approaching stranger earlier than dogs $(Z=-3.217, p=0.001)$, actually during the first 2 seconds. However, none of them showed any sign of intense fear, they did not try to run away or did not hold or wag their tail between legs, instead they stayed in a lying position or walked away and oriented somewhere else or were sniffing the ground. No wolf displayed any sign of aggression, but 5 individuals from the pet dog group showed some aggressive displays (growl, bark, attack) towards the approaching stranger $(p=0.039)$ (Fig. 1). Although dogs seemed to show somewhat more diverse behaviour responses (two friendly, two passive, five passive avoidant, two active avoidant, two threatening) than wolves (one friendly, 10 passive avoidant, one active avoidant), there was no significant difference between the two species with regard to their distribution in the final response categories $\left(\chi^{2}{ }_{(4)}=6.303, p=0.178\right)$.

After terminating the Threatening approach, E1 could pet all dogs and all but one wolves without evoking avoidance or aggression. One wolf was avoidant, but this individual behaved the same way also during the Friendly approach at the beginning of the test.

\subsection{Discussion}

The finding that, similarly to dogs, most wolves showed passive or friendly behaviour towards a friendly approaching unfamiliar human suggests that they were properly socialised to people. However, in the course of the Threatening approach wolves typically averted their gaze from the stranger earlier than dogs. Experimental evidence has already confirmed that even hand-reared and wellsocialised young wolves tend to avoid direct human eye contact in both problem solving (Miklósi et al., 2003) and communicational contexts (Gácsi et al., 2009). The readiness to make eye contact with humans in cooperative situations, which adult wolves seem to show (Gácsi et al., 2009), however, might be different from enduring the gaze of a human in ambiguous social situations. It is often claimed that the extended stare of a conspecific or a human could be a signal of dominance in canids (Fox, 1971). During intraspecific interactions subordinates break eye contact earlier than dominant individuals (Bradshaw and Nott, 1995), thus one might conclude that in the present experiment wolves behaved more submissively than dogs when encountering a threatening stranger. However, during the hand-raising period and their later life in the wolf park, these wolves could get used to familiar and unfamiliar humans staring at them. One explanation for the wolves' responses could be that these wolves considered direct human gaze from a distance of 4 metres even in the lack of any potentially competitive situation as a definite signal of dominance or threat, and that is why they averted their gaze. An alternative explanation could be that they simply were not concerned about the human after the friendly encounter and just took advantage of getting out of their enclosure and started to explore the location at which the testing was staged. The fact that none of the wolves showed any sign of aggressive displays during AS also supports the idea that wolves did not consider this test as representing a conflict or competitive situation. Thus, their gaze averting behaviour may be due to their ignorance of the human's behaviour or their general tendency to avoid human gaze. The agonistic behaviour of pet dogs in the same situation can be the result of the combination of various factors. The threatening human seemed to evoke mostly fear or mixed reactions of fear and aggression in dogs as described in detail by Vas et al. (2005, 2008).

The aforementioned differences between wolves and dogs support the role of domestication in shaping flexible and socially competent behaviours in interaction with humans. Three factors could account for the difference between dogs and wolves in the tendency for looking at the owner during the Threatening approach. First, several studies suggest that dogs tend to initiate eye contact with humans in communicative situations (Miklósi et al., 2003; Gácsi et al., 2009). Second, dogs show attachment behaviour towards their owners, which could not be observed in wolves (Topál et al., 2005), and therefore we assume that in this situation dogs consider the owner as a potential secure base. Finally, dogs might perceive the test as socially more challenging than wolves and they established eye contact with the owner in order to seek information in this ambiguous situation (social referencing, Merola et al., 2012 - see also later).

\section{Experiment 2}

Domestic dogs show playful behaviour throughout their lives and tend to engage also in interspecific play with humans (Hart, 1995), thus complex play situations provide a good possibility to investigate how dogs decode human communicative behaviours (Rooney et al., 2001). It has been suggested that dog-dog and dog-human play are 
structurally and motivationally distinct, thus the consequences of intraspecific play in the dog cannot be simply extrapolated to play with humans (Rooney et al., 2000). Recently, we have shown that in playful and non-playful situations dogs decode some human behavioural cues that communicate different modes (friendly vs. agonistic/ambivalent) of social interaction (Győri et al., 2010). Moreover, increasing evidence suggests that even competitive games between dogs and humans do not affect negatively the relationship of the partners as it was claimed earlier (e.g. McBride, 1995), and the correlations that have been revealed so far rather reflects the players already established dominance status. Thus, even allowing the dog to win competitive games should not directly affect the relationship between the dog and human, presumably because dogs are able to distinguish situations in which human partners' play signals are displayed or absent (Rooney et al., 2003; Tóth et al., 2008). Observing dog-human play bouts Rooney et al. (2001) found several human play signals to be effective in eliciting play, for example the forward lunge (sudden quick movement towards the dog), the vertical bow (bending at the waist until the torso is horizontal), chasing the dog or running away from it. Play signals were more successful at eliciting play when accompanied by play vocalizations.

Interestingly, there has been no report on wolf-human play in the literature that could be compared to dog-human play. There is a need for such comparative studies if one aims to explain the complexity in dog-human play (e.g. Mitchell 1991; Horowitz and Bekoff, 2004).

In a second experiment, therefore, we investigated whether a familiar human could successfully communicate a play situation in a competitive context (Object guarding game -OG) and evoke guarding behaviour from dogs or wolves by using friendly and playful behaviours. Furthermore, we investigated whether she could make the subject stop showing aggressive displays solely by ceasing the presentation of the playfully competitive behaviour pattern, and take away the guarded object without displaying any dominant/assertive behaviour.

Object guarding games can be described in terms of projects, routines, and enticements as suggested by Mitchell and Thompson (1991). The actions of players are organised in projects and the interactive coordination of projects leads to routines that are composed of compatible projects. However, if these repetitive action sequences (projects) are incompatible, one player can entice the other through self-handicapping to maintain or initiate play. Accordingly, in our study the project of the human is to (pretend to) take away the bag, which could be complemented by the dog's project to guard the object. Each project could be achieved by displaying adequate behaviours, that is, the human stretched out her hand and tried to grasp the bag (but actually never did it even if she could have grasped it), while the dog was expected to show guarding behaviour by displaying aggressive behaviours (e.g. growling or barking; for details see method section). The repeated challenges on the part of the human could be described as enticements as for every time before reaching the bag the human suddenly withdrew and started the challenge from the start again.
We compared the responses of the two species during both the game and the Take away episode of the interaction. We assumed that, in contrast to wolves, dogs would rapidly change their responses and flexibly adjust their behaviour according to the human's behaviour and communicative signals.

In addition, we compared the results of Experiment 1 and 2 to investigate the extent to which the agonistic behaviours displayed during AS and OG corresponded at the individual level.

\subsection{Method}

The same subjects $(N=26,13-13$ pet dogs and handreared wolves) were observed as in Experiment 1. At least two days elapsed between the two tests. The two tests took place at different locations that both were familiar to the subjects. In this situation a female who was familiar to both the dogs and wolves acted as the competitor (E2). This means that the dogs had met E2 before the tests several times. These interactions included physical contact (petting, stroking) and some play situations as well (e.g. object play).

The subject was tethered with a $2 \mathrm{~m}$ long leash to a tree and its owner stood beside the tree without moving or speaking. During the introductory and challenging episodes E2 wore a baseball cap (see below). The aim of this test was to induce object guarding behaviour in a playful interaction in which $\mathrm{E} 2$ challenged the subject for taking away the object. At the beginning of the test, she put her belt bag $(20 \mathrm{~cm} \times 10 \mathrm{~cm} \times 5 \mathrm{~cm})$ in front of the subject and pretended to aim at taking it away. It is important to note that this object in itself was irrelevant for defending, because it was not a toy, did not belong to the animal or its owner, and did not contain food or anything worth guarding. The actions performed by the human competitor were aimed to make it the target object of the game. The test was divided into three episodes.

1. Introductory episode: in order to introduce the playing context E2 called the subject's attention to the bag and communicated the playful nature of the encounter. This included greeting and petting the animal, showing the object to it and trying to play for a few seconds by moving the object in front of the animal. Then $\mathrm{E} 2$ made the subject lay down gently, placed the object in front of it within reach, and tapped several times playfully on it with her palm. This was accompanied by cheerful facial expressions and playful vocalisation. Then E2 stepped back 2-3 metres and stood facing the subject. Only those animals that showed interest in the unfamiliar object (sniffing, touching) when it was presented to them by E2 were tested in the next episode. We terminated the test prematurely with three dogs and four wolves because they did not show interest in the bag. One wolf was not tested because of health problems.

2. Game episode: E2 slowly approached the animal, similarly to the Threatening approach in AS test, but also stretching out her hand as if she aimed at reaching the object. She tried to maintain eye contact with the subject throughout the interaction. As soon as the animal made any sign of guarding behaviour (growl, bark, attack, snap), she jumped backwards and laughed. If the subject did 
not show guarding behaviour until E2 almost reached the object she retreated the same way. If the animal repeatedly moved away or turned its head away, she tried to attract its attention by clapping her hands or approaching it from a different direction. If the subject left the object and went to the owner or moved in another direction, then E2 resumed the first episode by introducing the playing context again. Four such repositions were allowed during the whole test. Only those animals that stayed near to the object for a minimum of 1 minute during the game were tested in the next episode. One dog and three wolves were excluded because they lost interest during the test.

3. Take away episode: finally E2 terminated the game, stopped the guarding provoking behaviour, stood about 23 metres from the subject and threw her baseball cap about $1 \mathrm{~m}$ from the object. This unexpected action was performed to distract the subject's attention from the guarded object for a second in order to let it re-evaluate the following actions of E2. She waited for 2-3 seconds, and then walked in a relaxed way towards the subject, talked to it kindly and stroked it and reached for the bag. If the animal did not show aggressive displays (bark, growl, snap) or guarded the bag putting its head/feet on it moving its nose towards E2's approaching hand, E2 got hold of the bag and tried to take it away without showing any sign of threatening behaviour (loud talk, commands, threatening gestures). If the animal pulled it back, E2 asked for it kindly and tried to take it away by stroking the animal's head.

The test lasted about 1-2 minutes depending on the number and length of the repositions, because their durations were not included in the duration of the Game episode, which lasted at least for 1 minute. Moreover, the Take away episode was started only when the subject was close to the object and oriented to E2.

\subsubsection{Behaviour variables and data analyses}

For most behaviour variables (see Table 1) occurrence or non-occurrence during the test was noted because exact duration could not be determined and the length of the tests varied depending on the reaction of the subjects. We defined guarding behaviour as the occurrence of growling and/or barking in the direction of E2, and/or snapping at E2 during the game part.

Since this test could be completed only with five wolves (see above), and the main behaviours often did not show variability within a species, the proportion of the subjects performing certain behaviours (Table 2) and qualitative description is provided for comparing dogs and wolves.

Inter-observer agreements for the variables were assessed by means of parallel coding of the $30 \%$ of the animals by two observers. High values were calculated in all cases (Kappa coefficients: grab object: 0.9; snap: 0.87; play signals: 1.0; allow take away: 0.9)

\subsection{Results}

Out of the nine dogs that could be involved in the game situation six showed some type of guarding behaviour when challenged for the bag. Only one of them snarled/growled at the familiar human, none snapped at her hand, but all six barked at her. One dog carried the bag to E2 before engaging in the guarding behaviour. At the termination of the game, all dogs allowed the human competitor to take hold of the object within 3 seconds. We did not observe such flexible changes in the wolves' behaviour. Actually, two out of the five wolves responded to the human's challenging behaviour with aggression (one growled and one snapped and attacked), and 3 showed friendly behaviours (tail wagging, face licking). From the friendly ones, two displayed play signals (pawing, rolling over with pawing legs). At the end of the test, irrespective of their previous reaction, none of the wolves let E2 take hold of the bag; two responded by grabbing it, one growled, one snapped at E2's hand, and one put its feet and head on the bag when E2 reached for it, and pushed her hand away with its nose. (see Fig. $2 \mathrm{a}$ and b). Even the owner could not take away the object from one wolf. It should be noted that wolves mainly reacted to E2's behaviour if her hand was very close to the bag (in 10-20 cm), however most dogs showed guarding behaviour already when she was 23 metres from them. None of the dogs displayed specific play signals, such as pawing or play bow.

The individuals of the two species showed different behaviours towards their owners too. When challenged by E2, all dogs gazed at their owner at least once and seven of them even approached the owner, but we could not observe these behaviours in wolves. (Table 2) Of the six dogs that showed guarding behaviours, four individuals gazed at the owner after the guarding response and two dogs did so before it.

\subsubsection{Behavioural associations across the two test situations}

Out of the five wolves that participated in both tests three showed aggression in OG and none in AS. The two individuals who looked at the owner in AS did not do so in OG. Out of the nine dogs that could be involved in OG, the same five individuals wagged their tails in both tests. All nine dogs looked at the owner in OG and all but one in AS. However, from the six individuals that showed aggressive displays (bark and/or growl and/or attack) in OG only two did so in AS, and one dog barked only in AS.

\subsection{Discussion}

The results supported our assumptions that a familiar human could not only evoke guarding behaviour (aggressive displays) in pet dogs by using friendly signals and enticement, but importantly she could also stop the subjects' guarding behaviour by ceasing the display of these signals. In contrast to dogs, wolves tended to show the same type of response during both the Game and Take away episodes not adjusting their behaviour to the changes in the human's signals. Moreover, wolves' but not dogs' aggressive displays could be regarded as predictive signals in this situation, because wolves that showed aggression during the Game episode did the same in the Take away episode and did not give up the object. These results can be interpreted as dogs being able to modify their behaviours in response to the human partner's behavioural changes, that is, they could flexibly complement the human's project in this complex social situation. 

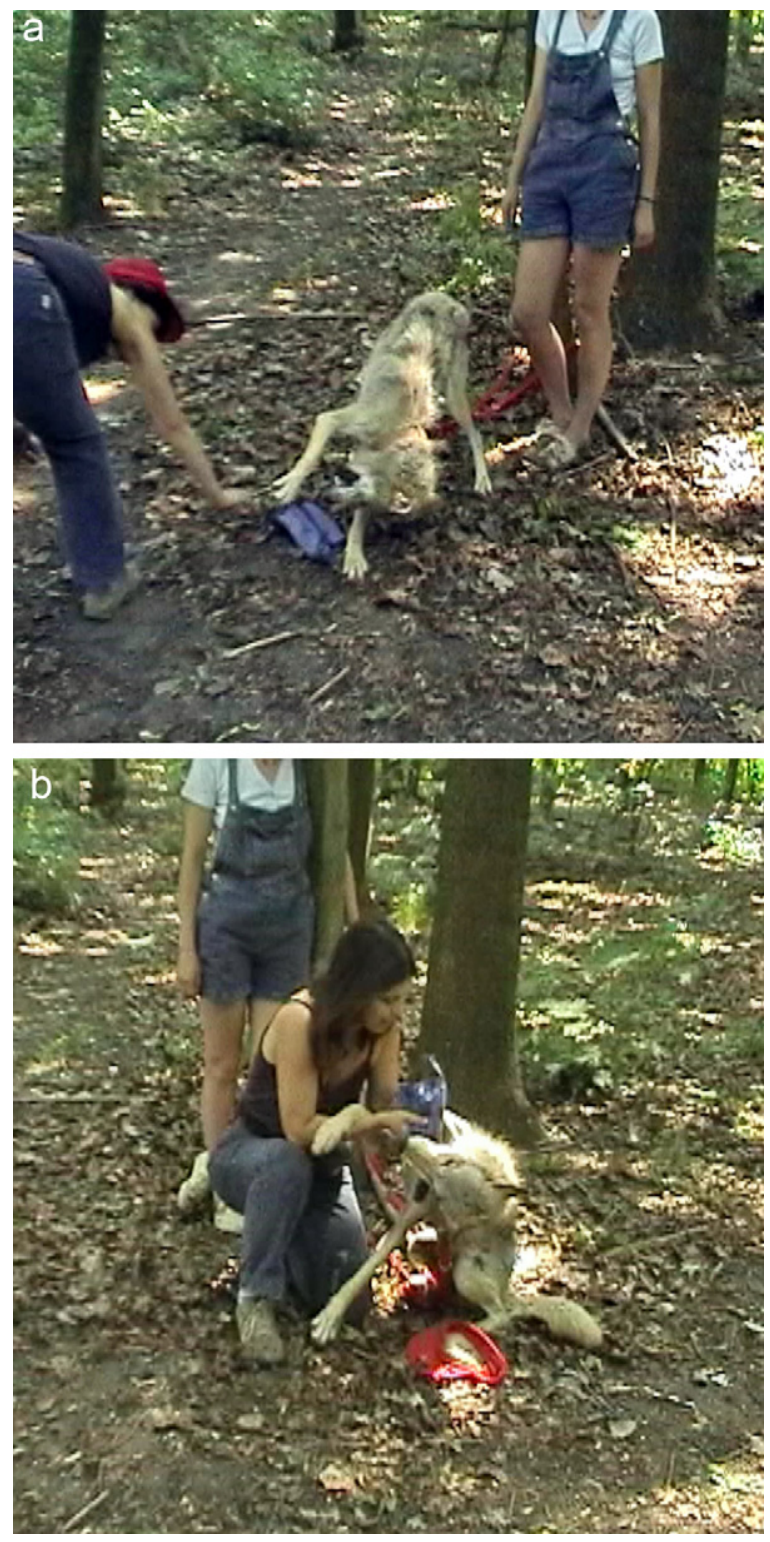

Fig. 2. Play behaviours of wolves in Object guarding test. Pawing in case of one of the two playful wolves during the Game episode (a), and playful grabbing and pulling during the Take away episode (b).

A further important finding is that none of the interacting wolves looked at the caretaker during the Game episode. This suggests a difference in their tendency to use their human caregivers for social referencing to guide their own understanding of such socially challenging, ambiguous situations. It is worth mentioning that looking at others when confronted with ambiguous events in order to use the emotional reactions of others to regulate their own behaviour is a 'behaviour tool' commonly used by human infants (Klinnert et al., 1986), and recently has been revealed in dogs (Merola et al., 2012). Our results raise the possibility that this functionally infant-analogue behaviour in dogs is one of the hallmarks of the fine-tunedness to humans of this domestic species. Alternatively, it is possible that the situation was not as challenging for wolves as it was for dogs, because wolves did not try to adjust their responses to the project of the human.

Importantly, these behavioural differences leave open the possibility of alternative but non-exclusive explanations. The tested wolves' and dogs' responsiveness might stem from differences in (1) the amount of experience in interspecific game situations; (2) their readiness to pay attention to humans' behaviour and to be involved in such inter-specific social interactions (see Gácsi et al., 2009); (3) their ability to change flexibly their behaviour and/or underlying inner states (Vas et al., 2005); (4) their ability to read the human partner's aims. Therefore, in addition to species-specific (evolutionary) differences, these differences in abilities and/or motivations might be due to rearing (developmental) differences. Note, however, that although wolves were living in packs when the experiments were carried out and might have had less opportunity to play with humans than dogs, they had extensive early socialisation and regular handling by the owners since then. Moreover, during the first few months owners played object games with the wolf pups, and during such games wolves, in contrast to dogs, showed aggression already at the age of 5-9 weeks (Győri et al., 2007).

The fact that the dogs allowed the human to take the bag when she finally reached for it can be explained by several factors. First, one might argue that some dogs (similarly to wolves) could be motivated to possess the bag, but at the end of the game only dogs accepted the familiar human's dominance even in the absence of any relevant behavioural signal of dominance. We should note, however, that in the case of wolves neither the dominant status nor the partner's dominant behaviour is effective to take away a small guarded object from a subordinate individual (Mech, 1970; Lockwood, 1979; Győri et al., 2007).

On the other hand, some dogs might not have been interested in possessing the object even during the game, but just showed some guarding behaviour as a response to the repeated enticements of the human partner. We might also consider that dogs had some understanding of the human partner's and their own role (project) in the game

Table 2

Behavioural data of the pet dogs and hand-reared wolves that could be involved in the Object guarding situation. (Percentages are presented due to different sample sizes.).

\begin{tabular}{|c|c|c|c|c|c|c|c|c|}
\hline \multirow[t]{2}{*}{ Proportion of subjects showing } & \multicolumn{4}{|c|}{ During game episode } & \multicolumn{4}{|c|}{ During take away episode } \\
\hline & Tail wagging & $\begin{array}{l}\text { Aggressive } \\
\text { display }\end{array}$ & $\begin{array}{l}\text { Gaze at } \\
\text { owner }\end{array}$ & $\begin{array}{l}\text { Approach } \\
\text { owner }\end{array}$ & Tail wag/lick & $\begin{array}{l}\text { Aggressive } \\
\text { display }\end{array}$ & $\begin{array}{l}\text { Grab } \\
\text { object }\end{array}$ & $\begin{array}{l}\text { Allow get } \\
\text { hold of }\end{array}$ \\
\hline $\operatorname{Dogs}(N=9)$ & $78 \%$ & $67 \%$ & $100 \%$ & $78 \%$ & $56 \%$ & $0 \%$ & $0 \%$ & $100 \%$ \\
\hline Wolves $(N=5)$ & $60 \%$ & $40 \%$ & $0 \%$ & $0 \%$ & $40 \%$ & $40 \%$ & $40 \%$ & $0 \%$ \\
\hline
\end{tabular}


(Mitchell and Thompson, 1991) and they reacted in line with the human's intention and displayed playful guarding. If so, their motivational status was not entirely consistent with their behaviour (aggressive displays and other possessive signals) which therefore, can be regarded as a kind of social play including elements of pretence. Even though the two playful wolves seemed to understand the playful nature of the interaction, they did not adjust their role to the project of the human, that is, first they did not guard the object and then did not allow the human to take it away. Dogs stopped to show possessive behaviour when the human partner stopped communicating the playful guarding aspect of the situation, and did not guard or grab the object any more.

To gain further insight to human-dog interactions in competitive game situations with humans we carried out a third experiment.

\section{Experiment 3}

To provide a deeper insight into the behaviour of dogs during the guarding game we carried out a third experiment, in which we tested a group of trained Belgian shepherds, a breed characterised as moderately aggressive during interactions with humans.

In this experiment, in addition to AS and OG situations trained Belgian shepherds were observed in a different guarding context, in a Food guarding (FG) situation. This was structurally similar to OG but differed in some respects. Importantly, the object to be guarded was biologically relevant to the context (a piece of meaty bone), and the human partner applied only enticement but did not display play signals. The notion that FG situation could be most effective in provoking not only aggressive communication (growling and barking) but also aggressive actions like snapping, biting and attacking, stems from studies applying test batteries to evaluate the dogs' tendency for aggressive behaviour (Netto and Planta, 1997; Klausz et al., 2009).

In this experiment we tested Belgian shepherd dogs because sheepdogs have been bred for working in close cooperation with the owner and for being a watchful guard of the flock and around the house. Further, we assumed that a tendency to display aggressive behaviours during interactions with humans is an important prerequisite for showing guarding behaviour. Belgian shepherds showed moderate tendency for aggressive behaviours in the Vas et al. (2005) study, which seemed ideal for our procedure. This way we hoped that, in contrast to Experiment 2, most subjects could be involved in the guarding test. Moreover, for this experiment we included only trained pet dogs with obedience and basic defence training. However, they were trained neither for protection work in real life situations (without the protective sleeves) nor to guard objects. (In defence training a familiar trainer, wearing special bite sleeves, acts as the "bad guy" during bite work for sport dogs.) We asked the owners about the possessiveness of their dogs and all owners claimed that they could take away a bone from their dog without evoking aggression. Importantly, wolves were not tested in this experiment because all their caregivers agreed that wolves could not be given the Food guarding test for safety reasons. Indeed, wolves proved to be aggressive in take away bone tests even at the age of 6-8 weeks (Györi et al., 2008).

We hypothesised that the comparative analyses of the dogs' behaviour in the two types of guarding tests would reflect the differences between the situations. We assumed that despite the considerably similar behaviour of the human during the challenge, the lack of play signals and the presence of a piece of preferred food would inhibit the emergence of playful inner state in the dog. We assumed that dogs would not interpret the FG situation as a game because a bone evokes more likely real possessive aggression than a bag that can be more easily transformed to an object of a game. Thus we assumed that dogs would not 'pretend' to guard the bone from the familiar experimenter. We expected them to either guard it after E2's challenging behaviour, but then not allow her to take hold of the bone, or alternatively, not dare to show aggressive displays in a seemingly not playful context (with regard to a relevant object and in the absence of the human's explicit communication of the playfulness of the situation).

\subsection{Method}

\subsubsection{Subjects}

We tested 13 Belgian shepherds, the mean \pm SD age of the dogs was 6.8 years \pm 3.9 ) and 12 individuals out of the 13 were males, none of them were castrated. (Vas et al., 2005. found no difference in the behaviour of males and females in Approaching Stranger test.) One dog's AS record could not be evaluated due to technical reasons. Eleven of the dogs came from a multi-dog household.

\subsubsection{Test situations}

The $O G$ and $A S$ situations were identical to the description in Experiment 1 and 2. The two guarding test situations, OG and FG were carried out in a balanced order, and AS was performed in randomised order: before, between or after the two guarding tests. At least one week elapsed between two tests. The three tests took place at different locations in the familiar park beside the dog school the given subject attended. In AS an unfamiliar female experimenter (E1), in OG and FG a familiar female experimenter (same as in Experiment 2) carried out the tests (E2). This means that the dogs have met the experimenter before the tests several times. These interactions included physical contact (petting, stroking) and some play situations as well (e.g. ball game).

FG situation was very similar to OG (see details there) but we used a meaty beef bone instead of E2's belt bag, and the human competitor did not communicate the playful nature of the encounter. The bone was placed in a small $(20 \times 30 \times 20 \mathrm{~cm})$ wire mesh cage to prevent the dog from chewing it or carrying it away. The owner placed the cage in front of the dog almost $2 \mathrm{~m}$ from the tree to which it was tethered, then said "it is yours", and at the same time made the dog lay down and not try to eat the bone ('wait'). Then the owner stepped back to the tree. After this E2, who stood 2-3 metres from the dog, acted as if she wanted to take the bone, and tried to facilitate the dog to display guarding behaviour. However, in this case she did not tap the cage 
Table 3

Behavioural data of the trained Belgian shepherds in the Object guarding and Food guarding situations.

\begin{tabular}{|c|c|c|c|c|c|c|c|}
\hline \multirow[t]{2}{*}{ Number of subjects showing } & \multicolumn{4}{|c|}{ During game episode } & \multicolumn{3}{|c|}{ During take away episode } \\
\hline & Tail wagging & $\begin{array}{l}\text { Aggressive } \\
\text { display }\end{array}$ & $\begin{array}{l}\text { Gaze at } \\
\text { owner }\end{array}$ & $\begin{array}{l}\text { High-pitched } \\
\text { vocal. }\end{array}$ & Tail wagging & $\begin{array}{l}\text { Aggressive } \\
\text { display }\end{array}$ & $\begin{array}{l}\text { Allow get } \\
\text { hold of }\end{array}$ \\
\hline Object guarding & 8 & 12 & 12 & 8 & 12 & 1 (bark) & 13 \\
\hline Food guarding & 7 & 10 & 9 & 9 & 11 & 0 & 13 \\
\hline
\end{tabular}

at the beginning of the test and did not laugh or clap hands during the repeated approaches. If the animal moved away or turned its head away, she tried to attract its attention by some neutral noise (coughing, scratching the ground) and/or approaching from a different direction. If the subject left the object and went to the owner or moved in another direction, then the owner made the subject lay back behind the cage and showed it the bone again (reposition).

All tests were video recorded from the side by a woman. The behavioural variables were coded and analysed later. None of the subjects had to be excluded because of lack of motivation, that is, they all showed interest both for the bag and the bone.

\subsubsection{Behaviour variables and data analyses}

During data analysis the same variables were used as in Experiment 1 and 2 with the following amendments. In addition to the variables listed in Table 1, the subjects' final behaviour in AS was categorised into response categories both in the Friendly approach and Threatening approach episodes (see details in Experiment 1). Based on our experiences in Experiment 2, we included a further behavioural variable in Experiment 3: high-pitched vocalisation. In Experiment 2, these behaviours were not frequent enough for statistical analyses because of the small number of subjects that completed the test. Interobserver agreements for high-pitched vocalisation were assessed by means of parallel coding of $30 \%$ of the animals by two observers; Kappa coefficient was 0.87 . (For all coded behavioural variables, see Table 1 ). Chi-square test of homogeneity or Fisher's exact test was applied when the distribution of the subjects in the different behaviour categories was analysed.

\subsection{Results}

\subsubsection{Reactions of trained Belgian shepherds in AS situation}

During the friendly greeting all subjects behaved in a passive $(N=10)$ or friendly $(N=2)$ way with E1. During the second approach, however, their behaviour changed strikingly. Most of them showed threatening $(N=6)$ or avoidant (active avoidant: $N=2$; passive avoidant: $N=1$ ) behaviour when they encountered the threatening human. Only three dogs did not change their friendly $(N=1)$ or passive $(N=2)$ behaviours. All five dogs that barked also attacked or growled at E1 (Fig. 1). All but two dogs gazed at the owner at least once during the Threatening approach, most of them before showing threatening behaviour towards the stranger.
In the Calling part, however, when E1 finally tried to stroke the dogs, none of them displayed any sign of aggression or fear and only one dog showed avoidance. During this contact all but one individuals wagged their tails and approached E1 within 3 seconds, thus more dogs displayed friendly behaviour towards the stranger after the Threatening approach than during the Friendly approach $(p<0.001)$.

\subsubsection{Behaviour of trained Belgian shepherds in $O G$ and FG situations (Table 3)}

Most of the dogs showed guarding behaviour in both situations, that is, they growled, barked and/or attacked the approaching familiar human. On the other hand, none of them snapped towards E2's hand in either situation even when her hand was very close to the belt bag or the bone, and about half of the dogs wagged their tail in both situations. (For typical behaviours in OG, see Fig. 3 af.) Interestingly, three dogs carried the bag to E2 and two dogs carried it to the owner before displaying guarding behaviours. With the exception of the one non-guarding dog, all subjects gazed at the owner during the Game episode in OG. Moreover, eight out of the 12 guarding dogs in OG gazed at or approached the owner right after their first aggressive display. In FG the same sequence could be observed only in the case of three individuals. Most of the guarding dogs emitted some high-pitched vocalisation (mostly bark, in some cases whine or growl), and in the case of seven individuals this type of vocalisation was the first sound type emitted during the Game episode of both situations.

Table 3.

Importantly, none of the dogs showed any form of aggression in the Take away episode in FG and only one barked once in the Take away episode in OG. Although most dogs seemed to switch from friendly behaviour to guarding behaviour during the Game episodes, and then again to friendly behaviour at the Take away episodes, none of the individuals displayed a play bow in either situation. All but one dog wagged their tails in OG and all but two in FG when stroked by E2 while taking away the guarded object. All dogs allowed E2 to get hold of the guarded object (bag or bone) in both tests within 3 seconds.

\subsubsection{Comparison of the responses in the three situations}

No difference in the pattern of the types of aggressive behaviours was revealed in the three encounters $(p=0.449)$, but it is important to note that barking alone (without growling or attacking) occurred only in the guarding situations (Fig. 4).

The proportion of dogs that gazed at the owner did not differ across the three situations $\left(\chi^{2}(2)=2.34\right.$, 

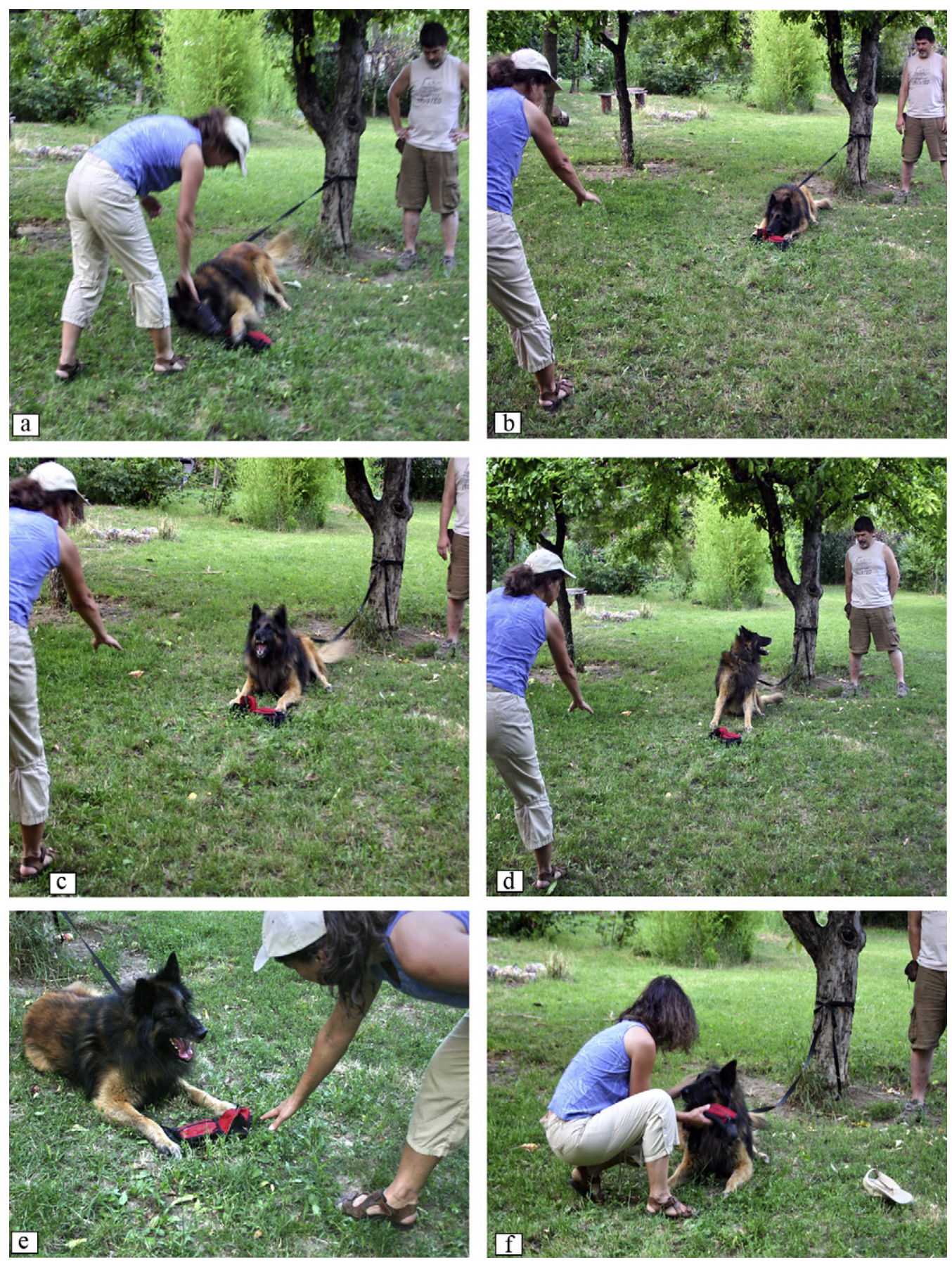

Fig. 3. Typical interactions with the dogs during Object guarding. a) introductory episode, b) challenging from $3-4 \mathrm{~m}, \mathrm{c}$ ) guarding behaviour (hand is far), d) gaze at owner, e) guarding behaviour (hand is close), f) take away.

$p=0.31)$. The approach of the owner was typical behaviour only in the OG test $\left(\chi^{2}(2)=9.019, p=0.011\right.$; OG vs. FG: $\chi_{(1)}^{2}=5.571, p=0.018$; OG vs. AS: $\left.\chi_{(1)}^{2}=7, p=0.015\right)$ (Fig. 5).

Some high-pitched vocalisation was displayed by most of the individuals during guarding, but it was almost lacking in $\mathrm{AS}\left(\chi^{2}{ }_{(2)}=10.874, p=0.004\right.$; OG vs. AS: $\chi^{2}{ }_{(1)}=7.667$, $p=0.006$; FG vs. AS: $\chi^{2}{ }_{(1)}=9.642, p=0.002$ ) (Fig. 5).

\subsection{Discussion}

Though none of the dogs showed avoidance or aggression towards the friendly approaching stranger, the pronounced aggression during the Threatening approach may be a feature of the breed (see Vas et al., 2005) and/or the subjects' defence training. Moreover, these dogs were friendlier with the stranger after than before the 


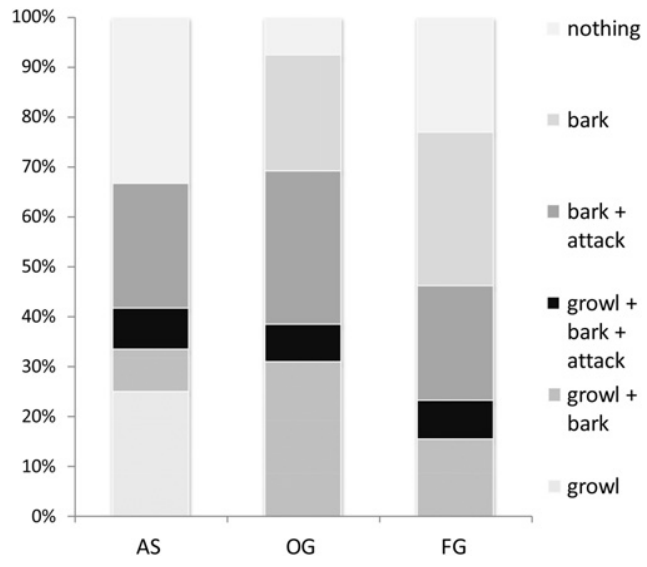

Fig. 4. Threatening behaviours of dogs in the three tests. The proportion of the Belgian shepherds that showed certain aggressive behaviour patterns in the three test situations: Approaching stranger (AS), Object guarding (OG), Food guarding (FG). Due to the different sample sizes (12 vs. 13) proportions are displayed instead of frequencies.

Threatening approach, which suggests that their aggressive displays during the Threatening episode could not be due to an overall high level of aggression towards humans but are related more to their sensitivity for the special context of the interaction.

The behaviour patterns of the trained Belgian shepherds were considerably homogeneous in OG situation, implying that breed and/or training effects may have important influence on their responses. We must stress, however, that even though they had participated in some defence training that included explicit aggressive behaviours (even bites) in game situations, they had no experiences with the contexts applied in the test procedure. Importantly, during the Game episode the dogs did not snap at the hand of the human, and all dogs allowed her to take hold of the object right after the game was terminated. Considering that in the sport training the dogs are supposed to bite when the person is in action, learned responses per se could not result in the observed behaviour.

The dogs did not display play signals during OG to confirm the playful nature of their aggressive displays, even

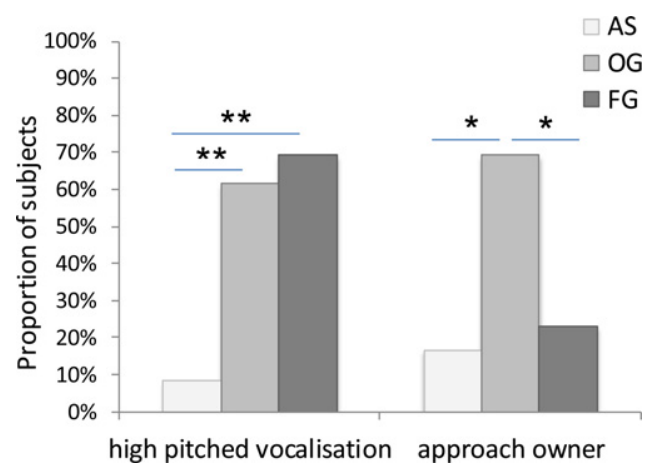

Fig. 5. Specific behaviours of dogs in the three tests. The proportion of the Belgian shepherds that showed high-pitched vocalisation and of those that approached the owner during the three test situations: Approaching stranger (AS), Object guarding (OG), Food guarding (FG). ${ }^{*} p<0.05$; ${ }^{* *} p<0.01$. though most of them showed definite signs of hesitation presumably because the consequence of their action was ambiguous (Bekoff, 1995; Györi et al., 2010). In this controlled game situation the endeavour to involve the passive owner in the interaction by gazing or approaching might have been an alternative solution to cope with the ambiguity (see also Merola et al., 2012).

Although the dogs' behaviour was somewhat different in the two guarding situations, the results only partly supported our initial hypotheses. In FG the specific enticement (e.g. self-handicap, moving back and forth) alone seemed to be effective to facilitate and reinforce guarding behaviour. Thus, it seems that in both guarding situations the familiar human's enticement was perceived by the dog as a relevant behaviour signal for encoding the project played by the human (Mitchell and Thompson, 1991). Especially in case of the trained dogs we can assume an ability to rely on a very diverse set of play signals due to the manifestation of ontogenetic ritualisation (Tomasello and Call, 1997), when a behavioural action becomes a part of a communicative signal set through the habitual interactions of two individuals. We should consider, however, that here dogs responded not to their owner's but a familiar human's signals in two unknown contexts.

The dogs approached the owner more frequently in OG, so it seems that FG situation was easier to interpret and/or more motivating for the dogs, even though most of them gazed at the owner also during this interaction. Frequent gazing in both OG and FG could be explained partly by the ambiguous social contexts, in which dogs had no previous experiences so they might use the owner as support or social reference, and partly by their intentions to check the owner's reactions to their aggressive displays.

The high-pitched vocalisation displayed by most Belgian shepherds in both guarding situations was not typical in AS. This type of vocalisation was produced mainly as the first vocalisation in the guarding tests, which could reflect dogs' uncertainty of their project at the beginning of the Game episode (one of the biologically relevant meanings of the use of high pitch is uncertainty of the speaker, see Gussenhoven and Chen, 2000). The unusual passive behaviour of the owner must have increased the ambiguity of the situation for the dogs, because they could not use the owner as a source of information or support (Merola et al., 2012). However, due to the familiar human's repeated enticements and the lack of the owner's interference, dogs seemed to recognise that they were expected or allowed to be involved in the interaction by guarding the object.

One explanation for the dogs' behaviour on a motivational basis could be that their motivational status simply changed as the interaction changed, that is, dogs switched from a neutral-friendly to an aggressive state (serious guarding) and then again to a non-aggressive state (giving up the object). Alternatively, they switched from a neutralfriendly state to a playful-aggressive state (pretended guarding) and then to a non-playful state. Nevertheless, for showing even playfully aggressive behaviour during the guarding part, dogs need to possess a capacity for a heightened level of aggressive inner state during interactions with humans. The fact that dogs did not attack or try to bite the 
human even at the end of FG situation supports the second explanation.

\section{General discussion}

In this study, we looked beyond some abilities that enable dogs to form peaceful mixed species groups with humans. The behaviours of pet dogs and extensively socialised hand-reared wolves were observed in different combinations of three test situations in which subjects interacted with a human partner. During these encounters the human's behaviour was designed to convey different types of aims by signalling friendliness, threat, play and competition. In most cases we found dogs' responses more congruent with the human's signals and actions.

In sum, we suggest three non-exclusive explanations for the subjects' behaviour in the two guarding situations, which may be combined to different extents depending on the context and the individual. First, the human's behaviour communicated a competitive social situation to the animal and her enticement behaviour gradually reinforced the evoked aggression. (Some wolves' behaviour seems to fit in this category.) However, in case of all dogs this aggression was partly inhibited by different factors (e.g. genetic effects due to domestication, learned rules in competitive situations), thus when the human stopped the challenging behaviour, the dogs' reactions changed rapidly. Second, subjects interpreted the human's enticement behaviour as initiating a social game and reacted in line with the human's aim by playful guarding behaviour. This could apply for some wolves during the guarding episode, but finally they did not switch back to non-playful behaviour and did not give up the object. Third, dogs comprehended some aspects of the humans aim from her behaviour pattern and played their role in the guarding game without being in a definite playful state (indicated by hesitative behaviours: approach owner, high-pitched vocalisation).

Although the present procedure does not allow us to make clear-cut differentiation at the species level, our results support the view that dogs have advanced abilities and readiness to combine seemingly contradicting behaviour responses to answer humans' behaviours or expectations, whilst wolves tend to display less human centred behaviours and adjust their behaviours less to that of the humans' in interspecific situations. We revealed that dogs are able to differentiate between pretended (Game episode) and real (Take away episode) competitive behaviour of a human partner and adjust their behaviours accordingly. In dogs both genetic and developmental factors might contribute to successfully participating in such complex forms of interspecific social play situations which might present ideal opportunity for dogs to "engage in those mental gymnastics that we call cognition" (Siviy, 1998). Further studies need to investigate whether some dog-human play could be described in terms of intentions, which include recognizing the human partner's goals and that play may include elements of pretence (Mitchell, 2002).

\section{Conclusion}

We conclude that in addition to the flexible utilisation of various conflict resolving behaviours (e.g. Győri et al., 2010), the ability in dogs to rely on human behavioural cues in ambiguous social situations might represent a fundamental element of dogs' social competence. Notwithstanding the effects of experience and learning, this ability of dogs to be drawn into such situations with humans could have been enhanced by domestication, leading to a more flexible manipulation of inner state and to a less deterministic relationship between motivational states and behavioural patterns (see Frank, 1980). The concerns raised by our present results need further investigations by observing wolves with more similar histories and different breeds of dogs in several playful contexts to gain more insight into the nature and mechanisms of dogs' flexible interspecific social behaviours.

\section{Acknowledgement}

Support for this work was provided by FP7-ICT LIREC 215554 and MTA 01031 . We are grateful to Zoltán Horkai and Dorottya Újvári from HORKAI Animal Co-ordination Team for their kind cooperation in working with the wolves. Special thanks to the wolf raisers for their devotion during the socialisation period, what made these tests possible. We thank all owners for their participation in our study and Bori Ferenczy for her help.

\section{References}

Bauer, E.B., Smuts, B.B., 2007. Cooperation and competition during dyadic play in domestic dogs, Canis familiaris. Anim. Behav. 73 (3), 489-499.

Bekoff, M., 1995. Cognitive ethology and the explanation of nonhuman animal behaviour. In: Roitblat, H.L., Meyer, J.A. (Eds.), Comparative Approaches to Cognitive Science. MIT Press, Cambridge, MA, pp. 119-150.

Bekoff, M., 1998. Intentional communication and social play: how and why animals negotiate and agree to play. In: Bekoff, M., Byers, J.A. (Eds.), Animal Play. Evolutionary, Comparative, and Ecological Perspectives. Cambridge University Press, New York, NY, pp. 97-113.

Bradshaw, J.W.S., Nott, H.M.R., 1995. Social communication and behaviour of companion dogs. In: Serpell the domestic dog. Cambridge University Press, Cambridge, 116-130.

Fagen, R., 1981. Animal Play Behaviour. Oxford University Press, Oxford.

Fox, M.W., 1971. Behaviour of Wolves, Dogs and Related Canids. Jonathan Cape, London.

Frank, H., 1980. Evolution of canine information processing under conditions of natural and artificial selection. Zeitschrift für Tierpsychologie 59, 389-399.

Gácsi, M., Győri, B., Miklósi, Á., Virányi, Zs., Kubinyi, E., Topál, J., Csányi, V., 2005. Species-specific differences and similarities in the behavior of hand-reared dog and wolf pups in social situations with humans. Dev. Psychbiol. 47, 111-122.

Gácsi, M., Győri, B., Virányi, Zs., Kubinyi, E., Range, F., Belényi, B., Miklósi, Á., 2009. Explaining dog wolf differences in utilizing human pointing gestures: selection for synergistic shifts in the development of some social skills. PLoS ONE 4, e6584.

Gussenhoven, C., Chen, A., 2000. Universal and language specific effects in the perception of question intonation. ICSLP 6 (2), 91-94.

Győri, B., Gácsi, M., Kubinyi, E., Virányi, Zs., Topál, J., Miklósi, Á., 2007. Comparative Investigation of Canid-Human interactions on Intensively Socialized Wolves and Differently Socialized Dog Pups. IEC, Halifax.

Győri, B., Gácsi, M., Miklósi, Á., 2010. Friend or foe: context dependent sensitivity to human behaviour in dogs. Appl. Anim. Behav. Sci. 128, 69-77.

Hart, L.A., 1995. Dogs as companions: review of the relationship. In: Serpell, J. (Ed.), The Domestic Dog. Cambridge University Press, Cambridge, pp. 162-178. 
Horowitz, A.C., Bekoff, M., 2004. Naturalizing anthropomorphism: behavioral prompts to our humanizing of animals. Anthrozoös 20, 23-35.

Klausz, B., Kis, B., Persa, E., Gácsi, M., 2009. Human-directed agression in shelter dogs: how to test for better prediction of outcomes. J. Vet. Behav. 4, 78.

Klinnert, M.D., Emde, R.N., Butterfield, P., Gampos, J.J., 1986. Social referencing: the infant's use of emotional signals from a friendly adult with mother present. Dev. Psychol. 22, 427-432.

Kubinyi, E., Virányi, Zs., Miklósi, Á., 2007. Comparative social cognition: from wolf and dog to humans. Comp. Cogn. Behav. Rev. 2, 26-46.

Lockwood, R., 1979. Dominance in wolves-useful construct or bad habit. In: Klinghammer, E. (Ed.), Symposium on the Behavior and Ecology of Wolves. Garland STPM Press, New York, pp. 225-245.

McBride, A., 1995. The human-dog relationship. In: Robinson, I. (Ed.), The Waltham Book of Human-Animal Interactions. Pergamon, London, pp. 99-112.

Mech, L.D., 1970. The wolf: the ecology and behavior of an endangered species. Doubleday Publishing Co, New York.

Merola, I., Prato-Previde, E., Marshall-Pescini, S., 2012. Dogs' social referencing towards owners and strangers. PLoS ONE 7 (10), e47653, http://dx.doi.org/10.1371/journal.pone.0047653.

Miklósi, Á, Kubinyi, E., Topál, J., Gácsi, M., Virányi, Zs., Csányi, V., 2003. A simple reason for a big difference: wolves do not look back at humans but dogs do. Curr. Biol. 13 (9), 763-767.

Mitchell, R.W., 2002. A history of pretense in animals and children. In: Mitchell, W.R. (Ed.), Pretending and Imagination in Animals and Children. Cambridge University Press, Cambridge, pp. 23-42.

Mitchell, R.W., Thompson, N., 1991. Projects, routines, and enticements in dog-human play. In: Bateson, P.P.G., Klopfer, P.H. (Eds.), Perspectives in Human Ethology, pp.189-216.

Mitchell, R.W., Thompson, N.S., 1993. Familiarity and the rarity of deception: two theories and their relevance to play between dogs (Canis familiaris) and humans (Homo sapiens). J. Comp. Psychol. 107 (3), 291-300.

Netto, W.J., Planta, D.J.U., 1997. Behavioral testing for aggression in the domestic dog. Appl. Anim. Behav. Sci. 52, 243-263.

O’Sullivan, E.N., Jones, B.R., O’Sullivan, K., Hanlon, A.J., 2008. The management and behavioural history of 100 dogs reported for biting a person. Appl. Anim. Behav. Sci. 114, 149-158.

Pellis, S.M., Pellis, V.C., 1998. Structure-function interface in the analysis of play fighting. In: Bekoff, M.M., Byers, J.A. (Eds.), Animal Play:
Evolutionary, Comparative, and Ecological Perspectives. Cambridge University Press, Cambridge, UK, pp. 115-140.

Reid, P.J., 2009. Adapting to the human world: dogs' responsiveness to our social cues. Behav. Proc. 80, 325-333.

Rooney, N.J., Bradshaw, J.W., 2003. Links between play and dominance and attachment dimensions of dog-human relationships. J. Appl. Anim. Welf. Sci. 6, 67-94

Rooney, N.J., Bradshaw, J.W.S., Robinson, I.H., 2000. A comparison of dog-dog and dog-human play behaviour. Appl. Anim. Behav. Sci. 66, 235-248.

Rooney, N.J., Bradshaw, J.W.S., Robinson, I.H., 2001. Do dogs respond to play signals given by humans? Anim. Behav. 61, 715-722.

Siviy, S.M., 1998. Neurobiological substrates of play behaviour: glimpses into the structure and function of mammalian playfulness. In: Bekoff, M., Byers, J.A. (Eds.), Animal Play. Evolutionary, Comparative, and Ecological Perspectives. Cambridge University Press, New York, NY, p. 237.

Tomasello, M., Call, J., 1997. Primate Cognition. Oxford University Press, Oxford.

Topál, J., Gácsi, M., Miklósi, Á., Virányi, Zs., Kubinyi, E., Csányi, V., 2005. Attachment to humans: a comparative study on hand-reared wolves and differently socialized dog puppies. Anim. Behav. 70, 1367-1375.

Topál, J., Miklósi, Á., Gácsi, M., Dóka, A., Pongrácz, P., Kubinyi, E., Virányi, Zs., Csányi, V., 2009. The dog as a model for understanding human social behavior. Adv. Study Anim. Behav. 39, 71-116.

Tóth, L., Gácsi, M., Topál, J., Miklósi, Á., 2008. Playing styles and possible causative factors in dogs' behaviour when playing with humans. Appl. Anim. Behav. Sci. 114, 473-484.

van der Borg, J.A.M., Netto, W.J., Planta, D.J.U., 1991. Behavioral testing of dogs in animal shelters to predict problem behaviour. Appl. Anim. Behav. Sci. 32, 237-251.

Vas, J., Topál, J., Gácsi, M., Miklósi, Á., Csányi, V., 2005. A friend or an enemy? Dogs' reaction to an unfamiliar person showing behavioural cues of threat and friendliness at different times. Appl. Anim. Behav. Sci. 94, 99-115.

Vas, J., Topál, J., Győri, B., Miklósi, Á., 2008. Consistency of dogs' reactions to threatening cues of an unfamiliar person. Appl. Anim. Behav. Sci. 112, 331-344

Virányi, Zs., Gácsi, M., Kubinyi, E., Topál, J., Belényi, B., Ujfalussy, D., Miklósi, Á., 2008. Comprehension of human pointing gestures in young human-reared wolves (Canis lupus) and dogs (Canis familiaris). Anim. Cogn. 11, 373-387. 